\title{
ANÁLISE DA OFERTA ALIMENTAR EM REFEIÇÕES DE UMA PRÉ-ESCOLA DA CIDADE DE SÃO PAULO
}

\section{ANALYSIS OF THE MENU OFFERED TO PRESCHOOL CHILDREN IN A PRIVATE SCHOOL IN SÃO PAULO}

\author{
Maria Carolina Henrique Vieira ${ }^{1}$ \\ Gabriela Farinha da Silva ${ }^{1}$ \\ Gabriela Sanches Périco Navarro' \\ Ana Isabel Furtado de Mendonça ${ }^{1}$ \\ Mônica Glória Neumann Spinelli² \\ Andrea Guerra Matias ${ }^{2}$
}

Resumo: O comportamento alimentar tem suas bases fixadas na infância. A qualidade e quantidade dos alimentos ingeridos pela criança são essenciais, uma vez que resultam em repercussões nas práticas alimentares, tendo a escola um papel determinante na construção desses hábitos. O objetivo deste estudo foi analisar qualitativamente e quantitativamente a refeição fornecida a alunos do ensino Infantil por uma escola privada da cidade de São Paulo. Para a avaliação da qualidade do cardápio mensal, foi aplicado o método de Avaliação Qualitativa das Preparações do Cardápio (AQPC) adaptado. Para quantificar o porcionamento per capita, foram considerados a quantidade de refeição servida e os alimentos colocados no prato em três dias. O consumo médio foi calculado descontando-se os restos. A qualidade do cardápio foi considerada adequada uma vez que foram fornecidos frutas, legumes e verduras todos os dias e não houve oferta de doces e sucos industrializados. O porcionamento médio foi de 248,81g per capita. Os restos representaram 20,75\%. Concluiu-se que houve um índice de resto considerável, o que torna necessária a busca por medidas para a redução de desperdícios.

Palavras-chave: nutrição da criança, cardápio, consumo de alimentos, desperdício de alimentos.

Abstract: The foundation of dietary behavior is acquired during childhood. The quality and quantity of food are essential, because they develop healthy eating habits. School also has a decisive role in the development of these habits. The main goal of this study was to analyze qualitatively and quantitatively the meal provided to children in a private preschool in São Paulo. A method of Qualitative Evaluation of Menu Components (QEMC) was applied and adapted, to evaluate the quality of the monthly menu. To quantify the per capita portioning, the number of meals served and the quantity of food placed on the plate were considered, for three days. The average consumption was calculated by excluding the leftovers. The quality of the menu was considered appropriate, because fruit and vegetables were provided every day, and sweets and processed juices were not offered. The averaged portioning was $248.81 \mathrm{~g}$ per capita. The leftovers represented $20.75 \%$. It was concluded that there was a significant amount of leftovers, which makes more research necessary to reduce the waste.

Keywords: child nutrition, menu planning, food consumption, food wastefulness.

\footnotetext{
1 Graduanda do curso de Nutrição - Universidade Presbiteriana Mackenzie - UPM. E-mails: cahhhh_14_@hotmail.com; gabi_1223@hotmail.com; gabriela242@msn.com; menfur.isabel@gmail.com.

${ }^{2}$ Doutora em Saúde Pública (área de concentração - nutrição) - Universidade de São Paulo - USP. Docente do curso de Nutrição - UPM. E-mails: spinelli@mackenzie.br; acgmatias@gmail.com.
} 


\section{INTRODUÇÃO}

Embora uma alimentação adequada na infância reflita no crescimento e desenvolvimento fisiológico, na saúde e bem estar da criança, estudos realizados em algumas cidades brasileiras mostram que o sobrepeso e a obesidade atingem $30 \%$ ou mais das crianças e adolescentes, fato explicado, em parte, pelas alterações no estilo de vida e nos hábitos alimentares, como o aumento no consumo de alimentos ricos em açúcares simples e gordura e a diminuição da prática de exercícios físicos (OLIVEIRA; FISBERG, 2003; ALBIERO; ALVES, 2007).

No Brasil, o Sistema de Vigilância Alimentar e Nutricional (BRASIL, 2009) indica o baixo consumo de frutas e, principalmente, de verduras e legumes na infância e o consumo elevado de alimentos não saudáveis, como biscoitos salgados, salgadinhos de pacote, doces e biscoitos recheados. Com o intuito de modificar essa realidade, é fundamental promover ações de educação alimentar e nutricional para incentivar hábitos alimentares saudáveis, pois é nessa fase da vida que são incorporados novos hábitos alimentares, relacionados ao descobrimento de novos sabores, texturas, cores e experiências sensoriais que irão influenciar o padrão alimentar na fase adulta (MINISTÉRIO DA SAÚDE, 2005; MENEGAZZO et al., 2011; RODRIGUES; FIATES, 2012).

Como mencionado anteriormente, o comportamento alimentar tem suas bases fixadas na infância; portanto, a escola é um espaço importante de socialização e de construção do conhecimento e senso crítico, embora os hábitos alimentares estejam arraigados nas práticas familiares (MOTTA; BOOG, 1991).

Segundo Bueno, Marchiori e Fisberg (2003), existe uma proporção relevante e crescente de crianças em idade pré-escolar, tanto em serviços institucionalizados públicos quanto particulares. Para as autoras, a escassez de estudos representativos, com essa população, faz com que sejam necessárias mais pesquisas que avaliem a ingestão alimentar dentro dos serviços institucionalizados, visando à melhoria do estado nutricional dessas crianças.

Escolas particulares, estudadas por Rodrigues e Fiates (2012), relataram que o consumo de legumes e verduras se dá, muitas vezes, por pedido ou exigência dos pais. Nenhuma criança associou o consumo de frutas, legumes e verduras ao ambiente escolar, o que é preocupante já que as crianças passam grande parte do seu tempo nas escolas, especialmente as que realizam as refeições principais nesse ambiente.

O ambiente escolar deve fornecer refeições e lanches de qualidade, que englobem aspectos nutricionais e higiênicos, que visem à segurança alimentar e nutricional da comunidade escolar, e que respeitem o prazer e o hábito cultural. Os alimentos fornecidos às crianças devem satisfazer parte de suas exigências biológicas, sendo essencial que possam ser aproveitados pelo organismo e tenham condição de exercer sua função nutricional. Eles também devem ser inócuos, uma vez que as Doenças Transmitidas por Alimentos (DTA) são uma das principais causas que contribuem para os índices de morbidade no país (AMORIN 
et al., 2012; OLIVEIRA et al., 2013).

Um modo de prevenir o aparecimento de doenças, melhorar, manter ou recuperar a saúde se dá por meio do cardápio que pode ser utilizado para a educação nutricional. Esse, de maneira geral, deve apresentar variedade nos alimentos selecionados, nas combinações, temperos, cores, formas, cortes, técnicas de preparo e modo de apresentação e/ou decoração. As opções disponibilizadas e a possibilidade de escolha significam oferecer ao comensal a oportunidade de decidir o que prefere consumir, como e onde (PROENÇA et al., 2005).

O ambiente escolar é fundamental para a determinação dos hábitos alimentares de préescolares e escolares, visto que a criança permanece no local durante um ou dois períodos do dia, convivendo com educadores, cuidadores e outras crianças que irão auxiliar e influenciar a formação de seus valores e estilo de vida, incluindo a alimentação (MENEGAZZO et al., 2011).

Nesse contexto, este estudo se propõe a avaliar qualitativamente e quantitativamente refeições oferecidas a alunos de pré-escola no município de São Paulo.

\section{METODOLOGIA}

Trata-se de um estudo de delineamento transversal observacional, realizado em uma escola privada da cidade de São Paulo.

Avaliou-se a refeição almoço servida a alunos de ensino infantil, de ambos os sexos, na faixa etária de 2 a 6 anos, durante três dias úteis, em 2013.

O cardápio mensal do refeitório foi solicitado para a avaliação de sua qualidade nutricional.

A avaliação da qualidade do cardápio mensal foi feita pelo método de Avaliação Qualitativa das Preparações do Cardápio (AQPC) adaptado (VEIROS; PROENÇA, 2003). De acordo com Prado, Nicoletti e Faria (2013), trata-se de um método utilizado para avaliar a qualidade nutricional das preparações de um cardápio elaborado, em número e porcentagem e analisar técnicas de cocção empregadas nas preparações, atentando-se para a monotonia e a repetição.

Para quantificar o porcionamento per capita dos alunos, foi calculada a quantidade de cada alimento servido. O cálculo foi feito por intermédio da média de quantidade distribuída por tipo de preparação dos três dias estudados, dividindo-se pela média do número de refeições servidas nesse mesmo período, obtendo-se, então, o porcionamento médio do prato de cada criança.

Os restos foram pesados, na sua totalidade, e calculados em porcentagem do total servido. 
O consumo médio foi calculado a partir da diferença entre valor servido e porcentagem de restos.

Os dados foram tabulados no Programa Microsoft Office Excel, com a elaboração de tabelas e gráficos, para a melhor visualização dos resultados.

Com relação às questões éticas, a instituição colaborou com a pesquisa, assinando um termo de consentimento.

Quadro 1 - Cardápio de almoço oferecido aos alunos da educação infantil de uma instituição privada da cidade de São Paulo, 2013

\begin{tabular}{|c|c|c|c|}
\hline $\begin{array}{l}\text { Componentes do } \\
\text { cardápio }\end{array}$ & Dia 1 & Dia 2 & Dia 3 \\
\hline Salada 1 & $\begin{array}{lll}\text { Alface } & \text { crespa } & \text { em } \\
\text { tiras } & & \\
\end{array}$ & Alface roxa em tiras & $\begin{array}{lll}\text { Alface } & \text { crespa } & \text { em } \\
\text { tiras } & & \end{array}$ \\
\hline Salada 2 & $\begin{array}{l}\text { Grão de bico com } \\
\text { amendoim }\end{array}$ & Tomate em cubos & Beterraba ralada \\
\hline Salada 3 & Tomate em cubos & Couve com bacon & Tomate em cubos \\
\hline Prato Base & Arroz + Feijão & Arroz + Feijão & Arroz + Feijão \\
\hline Prato proteico 1 & Moqueca de cação & $\begin{array}{l}\text { Filé de frango } \\
\text { grelhado }\end{array}$ & $\begin{array}{l}\text { Bife ao molho escuro } \\
\text { em tiras }\end{array}$ \\
\hline Prato proteico 2 & $\begin{array}{l}\text { Bife ao molho } \\
\text { madeira em tiras }\end{array}$ & Bife à role em tiras & Filé de coxa grelhada \\
\hline Guarnição 1 & Purê de batata & Batata com ovos & $\begin{array}{l}\text { Purê de batata } \\
\text { gratinado }\end{array}$ \\
\hline Guarnição 2 & Acelga refogada & Milho refogado & Abobrinha grelhada \\
\hline Guarnição 3 & Cenoura ralada & Chuchu com ovos & Salsicha com batata \\
\hline Sobremesa & Mexerica & Maçã & Banana \\
\hline
\end{tabular}

\section{RESULTADOS E DISCUSSÃO}

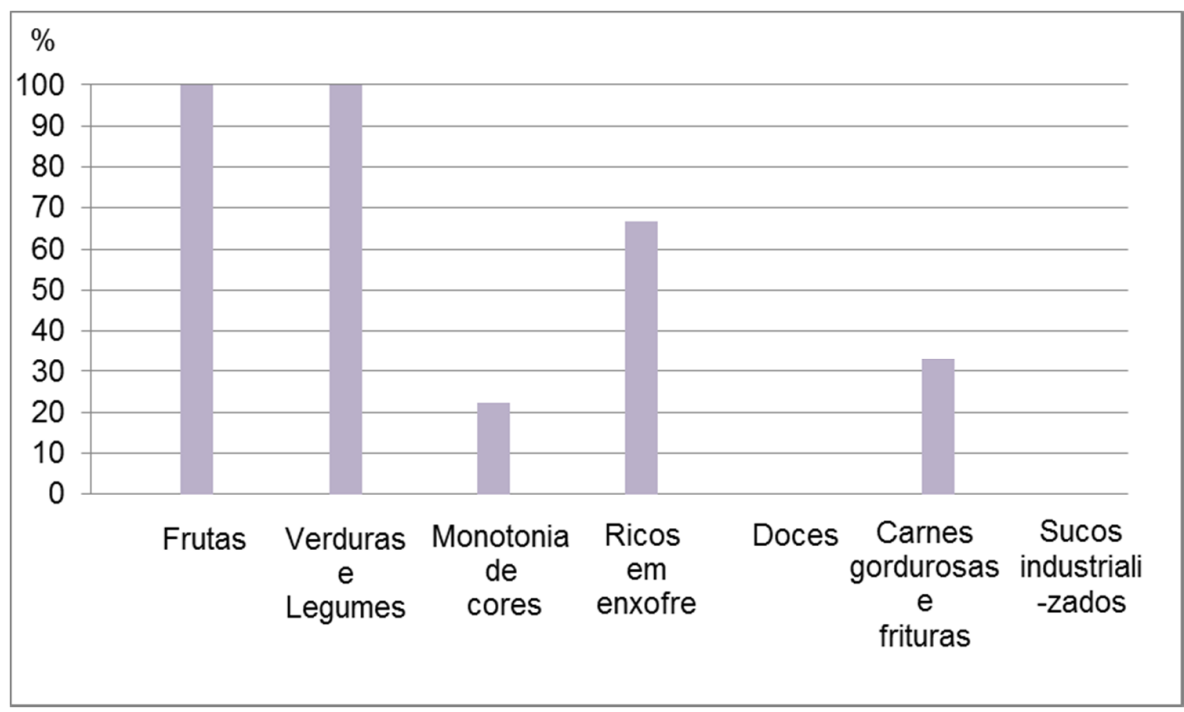

Figura 1 - Avaliação qualitativa do cardápio mensal, baseada no método de Avaliação Qualitativa das Preparações do Cardápio (AQPC), São Paulo, 2013. 
A aplicação do método de Análise Qualitativa das Preparações do Cardápio (AQPC) evidenciou a presença de frutas, verduras e legumes, todos os dias. Já, no estudo de Menegazzo et al. (2011), que teve como objetivo avaliar a qualidade do cardápio oferecido aos Centros de Educação Infantil de um município de Florianópolis, em apenas um dia do mês, foi oferecida mais de uma porção de fruta $(4,0 \%)$; em quatro dias, foi servida salada de folhosos $(16,0 \%)$; e, em apenas doze dias $(48,0 \%)$, foram oferecidas duas porções de verduras e legumes.

De acordo com o Ministério da Saúde (2005), é necessário variar o tipo de frutas, legumes e verduras consumidos durante a semana. Para alcançar o número de porções recomendadas, é necessário que esses alimentos estejam presentes em todas as refeições e lanches do dia. É indicado que a preferência seja frutas, legumes e verduras crus. Para a elaboração do cardápio, deve-se procurar combinar verduras e legumes de maneira que o prato fique colorido, garantindo, assim, diferentes nutrientes.

O cardápio analisado apresentou $22,2 \%$ de monotonia de cores. No trabalho de Veiros e Proença (2003), em que o cardápio de uma Unidade de Alimentação e Nutrição foi avaliado pelo método AQPC, teve-se $65,1 \%$ de preparações com semelhança de cores, valor correspondente a, aproximadamente, o triplo do encontrado no presente estudo. Já, Vidal et al. (2012) não encontraram nenhuma preparação com monotonia de cores. Para evitar monotonia de cores, o cardápio deve ser elaborado com a inclusão de frutas e hortaliças. Esses alimentos possuem uma variedade de cores que proporcionam agradável aspecto visual das preparações, uma vez que, quanto mais colorida, maior a variedade de nutrientes, como fibras, vitaminas e minerais.

Em relação a alimentos ricos em enxofre, observaram-se $66,7 \%$ de ocorrência, valor superior ao encontrado no estudo de Prado, Nicoletti e Faria (2013), de 40\%. Os alimentos sulfurados podem causar sensação de mal-estar pelo desconforto gástrico gerado (VEIROS; PROENÇA, 2003).

A frequência de carnes gordurosas e frituras foi de 33,3\%, valor superior ao encontrado por Veiros e Proença (2003), de 15,6\%. Segundo Prado, Nicoletti e Faria (2013) o consumo excessivo de gordura saturada e colesterol pode levar à obesidade, dislipidemias, doenças ateroscleróticas e doenças relacionadas, como cânceres e doenças cardiovasculares. Apesar disso, muitos serviços de alimentação optam por oferecer esse tipo de carne por serem de menor custo e atrativas aos comensais.

O cardápio elaborado não ofereceu sucos industrializados e doces. Como bebida, serviram-se sucos naturais e água e, como sobremesa, uma fruta. Estudos sobre os padrões alimentares de crianças e adolescentes, realizados no Brasil e em outros países, mostram elevado consumo de sucos industrializados, refrigerantes, alimentos ricos em açúcar e gordura, e baixo consumo de leite, frutas e hortaliças, que são práticas alimentares desfavoráveis, por estarem associadas a alto risco de doenças crônicas não transmissíveis (CARMO et al., 2006). 
Tabela 1 - Quantidade total ofertada de cada preparação em gramas (g) e porção média por criança, São Paulo, 2013

\begin{tabular}{lrrrrr}
\hline \multicolumn{1}{c}{ Categorias } & 1 dia (g) & 2 dia (g) & 3 dia (g) & $\begin{array}{c}\text { Total } \\
\text { nos três } \\
\text { dias (g) }\end{array}$ & $\begin{array}{c}\text { Média } \\
\text { porcionada por } \\
\text { criança (g) }\end{array}$ \\
\hline Salada 1 & 149,38 & 52,44 & 82,16 & 283,98 & 3,26 \\
Salada 2 & 50,00 & 234,60 & 102,99 & 387,59 & 4,45 \\
Salada 3 & 191,16 & 141,30 & 173,60 & 506,06 & 5,82 \\
Arroz & 1632,96 & 1137,40 & 1632,15 & 4402,51 & 50,60 \\
Feijão & 2003,00 & 1294,02 & 1965,30 & 5262,32 & 60,49 \\
Prato Proteico 1 & 707,52 & 721,31 & 871,20 & 2300,03 & 26,44 \\
Prato Proteico 2 & 1058,40 & 562,80 & 691,24 & 2312,44 & 26,58 \\
Guarnição 1 & 2905,50 & 257,39 & 2163,78 & 5326,67 & 61,23 \\
Guarnição 2 & 36,12 & 196,02 & 0,00 & 232,14 & 2,67 \\
Guarnição 3 & 23,84 & 128,40 & 480,60 & 632,84 & 7,27 \\
Nº de refeições servidas & 32 & 21 & 34 & 87 & - \\
\hline
\end{tabular}

O presente estudo analisou 87 almoços distribuídos aos alunos. O porcionamento médio oferecido (Tabela 1), quantificado nos três dias estudados, foi de 248,81 gramas por criança. Esse número não se refere ao consumo, tendo em vista que os restos, deixados por praticamente todas as crianças, não foram descontados. Outros estudos apresentaram resultados semelhantes - o de Franciozi e Spinelli (2012), em que se observou um porcionamento médio de 223,78 gramas para crianças na faixa etária de 2 a 10 anos, de uma instituição de ensino particular, e o de Pioltine e Spinelli (2012), com consumo médio de 203,5g para crianças de 2 a 5 anos e 408,7g para crianças entre 6 e 10 anos. Já, no trabalho de Faquim, Oliveira e Spinelli (2012), observou-se que o consumo alimentar de crianças entre 5 e 6 anos variou entre 120,8 e 243,7 gramas.

Em relação ao grupo das saladas, a Tabela 1 mostra as médias porcionadas dos três tipos de saladas, variando entre 3,26 e 5,82g, totalizando a média de 13,53g por aluno, valor muito baixo quando comparado às recomendações da Organização Mundial da Saúde (WHO, 2002). Estudo de Franciozi e Spinelli (2012), também realizado em uma instituição de ensino particular, encontrou valores variando entre 5,81 e 12,21g. De acordo com o Ministério da Saúde (2005), as verduras, frutas e legumes são alimentos ricos em vitaminas, minerais e fibras e devem estar presentes diariamente nas refeições, uma vez que contribuem para a proteção à saúde e diminuição do risco de ocorrência de diversas doenças.

O consumo de frutas não pôde ser avaliado devido à recusa da grande maioria das crianças por tal grupo. A baixa preferência das crianças por esses alimentos pode ser prejudicial à saúde. O Ministério da Saúde (2005) recomenda o consumo de três porções de frutas e três porções de legumes e verduras. Segundo Figueiredo, Jaime e Monteiro (2008), o consumo insuficiente desses alimentos está entre os dez principais fatores de risco para a carga total global de doença em todo o mundo. O consumo regular de uma variedade de frutas, legumes e verduras, juntamente com alimentos ricos em carboidratos pouco 
processados, oferece garantia contra a deficiência da maior parte de vitaminas e minerais, isoladamente ou em conjunto, aumentando a resistência às infecções (MINISTÉRIO DA SAÚDE, 2005).

As frutas e hortaliças são essenciais para uma dieta saudável e seu consumo em quantidade adequada, segundo a Organização Mundial da Saúde (WHO, 2002), deve ser de, no mínimo, 400g diárias, sendo equivalente a cinco porções. Possivelmente com as quantidades consumidas na escola estudada - valores baixos de hortaliças e a recusa das frutas - a quantidade diária recomendada não seja atingida.

A promoção do consumo desses alimentos é assegurada por meio de políticas públicas, com o intuito de aumentar o consumo, a produção e comercialização desses alimentos, promovendo a saúde e a segurança alimentar e nutricional das famílias (PRADO; NICOLETTI; FARIA, 2013).

A Tabela 1 mostra a oferta média de $50,6 \mathrm{~g}$ de arroz e $60,49 \mathrm{~g}$ de feijão. Resultados semelhantes foram encontrados no estudo de Faquim, Oliveira e Spinelli (2012), com $55 \mathrm{~g}$ de arroz e $80 \mathrm{~g}$ de feijão a crianças de 5 a 6 anos. Já, Pioltine e Spinelli (2012) obtiveram uma variação de porção, para pré-escolares entre 2 e 5 anos, de 29 a $36 \mathrm{~g}$ de arroz branco e 21 a $37 g$ de feijão. Segundo o Ministério da Saúde (2005), os cereais, como o arroz, são classificados como carboidratos complexos e são fontes de energia, de vitaminas do complexo $\mathrm{B}$ e de ácidos graxos essenciais que participam do metabolismo do sistema nervoso. Uma alimentação saudável deve incluir os carboidratos complexos em grande quantidade (45\% a $65 \%$ do VET) e fibras alimentares. Em relação às leguminosas (feijões), recomenda-se a ingestão de uma porção por dia. São alimentos ricos em proteínas e devem corresponder a, no mínimo, 5\% do total de energia diária (MINISTÉRIO DA SAÚDE, 2005).

A média porcionada, em relação aos pratos proteicos, esteve ao redor de 26,5 gramas. Tal número corresponde, aproximadamente, à metade da média porcionada encontrada no estudo de Franciozi e Spinelli (2012), de 52,05 gramas. De acordo com o Ministério da Saúde (2005), as proteínas devem corresponder de 10 a 15\% do valor energético total. São fundamentais, uma vez que fornecem os aminoácidos, substâncias importantes e envolvidas em, praticamente, todas as funções bioquímicas e fisiológicas do ser humano.

O grupo das Guarnições variou, significantemente, de acordo com a preparação (de 2,67 a 61,23 gramas). Na coleta de dados, foi observada a preferência por preparações à base de batata, responsáveis por maior parte da média porcionada de Guarnição 1. No trabalho de Franciozi e Spinelli (2012), o cardápio avaliado forneceu apenas um tipo de guarnição por dia e a média porcionada para esse grupo foi de $24,97 \mathrm{~g}$. Houve o fornecimento de outros tipos de guarnições, compostas, principalmente, por legumes. 
Tabela 2 - Restos alimentares diários em gramas (g) e em percentual (\%) do almoço oferecido, São Paulo, 2013

\begin{tabular}{lrrrr}
\hline Dia & $\begin{array}{c}\text { Quantidade } \\
\text { distribuída (g) }\end{array}$ & $\begin{array}{c}\text { Quantidade } \\
\text { consumida } \\
\mathbf{( g )}\end{array}$ & Restos (g) & Restos (\%) \\
\hline 1 & 8757,88 & 7424,16 & 1333,72 & 15,23 \\
2 & 4725,68 & 3686,42 & 1039,26 & 22,00 \\
3 & 8163,02 & 6119,21 & 2043,81 & 25,03 \\
Média & 7215,52 & 5743,26 & 1472,26 & 20,75 \\
\hline
\end{tabular}

O resto médio encontrado foi de $20,75 \%$. Neste estudo, o fato do porcionamento ser feito pelo funcionário provavelmente contribuiu para esse índice. Outros fatores que podem contribuir são: o alimento não ser hábito da criança, o modo de preparo, tipo de corte e temperos, entre outros (ABREU; SPINELLI; PINTO, 2013).

O cálculo dos restos é um fator limitante do estudo, uma vez que os alimentos não estão presentes no rejeito na mesma proporção em que se encontram na alimentação oferecida, porém, na impossibilidade de separação dos restos, optou-se por esse método.

Segundo Abreu, Spinelli e Pinto (2013), os restos devem ser próximos a zero, uma vez que valores altos demonstram uma falta de integração entre o serviço de alimentação e seu público.

O estudo realizado por Pioltine e Spinelli (2012) verificou a prevalência de 19,4 \% de resto, resultado próximo ao encontrado no presente estudo. Tal característica aponta a necessidade de elaboração e execução de programas de educação nutricional para esse público, a fim de evitar desperdícios.

\section{CONCLUSÃO}

Embora a qualidade nutricional do cardápio fornecido aos pré-escolares possa ser considerada adequada, uma vez que houve oferta de frutas, legumes e verduras todos os dias e não houve oferta de doces e bebidas industrializadas; na prática, o consumo ocorre de maneira irregular e inadequada, sinalizando para a necessidade de programas de educação alimentar.

A análise dos resultados do presente estudo permite concluir que o porcionamento médio encontrado $(248,81 \mathrm{~g})$ foi semelhante ao de outros estudos.

A porcentagem de restos obtida (20,75\%) foi elevada, considerando que esse valor deve ser próximo a zero. Fazem-se necessárias medidas que visem à redução dos restos, como o estabelecimento de um sistema de self-service monitorado, para que a criança crie seu padrão de consumo, diminuindo, assim, a alta porcentagem de restos. 


\section{REFERÊNCIAS}

ABREU, E. S.; SPINELLI, M. G. N.; PINTO, A. M. S. Gestão de unidades de alimentação e nutrição: um modo de fazer. 5. ed. São Paulo: Metha, 2013.

ALBIERO, K. A.; ALVES, F. S. Formação e desenvolvimento de hábitos alimentares pela educação. Nutr. Pauta, São Paulo, v. 15, n. 82, p. 1676-2274, 2007.

AMORIM, N. F. A. et al. Implantação da cantina escolar saudável em escolas do Distrito Federal, Brasil. Rev. Nutr., Campinas, v. 25, n. 2, p. 203-217, 2012.

BRASIL. Ministério da Saúde. Coordenação-Geral da Política de Alimentação e Nutrição Análise dos Registros do Consumo Alimentar. Boletim SISVAN n. 10. Brasília: MS; 2009.

BUENO, M. B.; MARCHIORI, D. M. L.; FISBERG, R. M. Evolução nutricional de crianças atendidas em creches públicas no Município de São Paulo, Brasil. Rev. Panam Salud Publica, Washington, v. 14, n. 3, p. 165-170, 2003.

CARMO, M. B. et al. Consumo de doces, refrigerantes e bebidas com adição de açúcar entre adolescentes da rede pública de ensino de Piracicaba, São Paulo. Rev. Bras. Epidemiol., São Paulo, v. 9, n. 1, p. 121-130, 2006.

FAQUIM, N. B.; OLIVEIRA, T.; SPINELLI, M. G. N. Porcionamento, consumo e desperdício em um restaurante escolar. Rev. UNIVAP., São José dos Campos, v. 18, n. 31, p. 71-77, 2012.

FIGUEIREDO, I. C. R.; JAIME, P. C.; MONTEIRO, C. A. Fatores associados ao consumo de frutas, legumes e verduras em adultos da cidade de São Paulo. Rev. Saúde Pública, São Paulo, v. 42, n. 5, p. 777-85, 2008.

FRANCIOZI, T. M. M.; SPINELLI, M. G. N. Porcionamento e Desperdício em Unidade de Alimentação Escolar. Nutr. Pauta, São Paulo, v. 21, n. 118, São Paulo, 2013.

MENEGAZZO, M. et al. Avaliação qualitativa das preparações do cardápio de centros de educação infantil. Rev. Nutr., Campinas, v. 24, n. 2, p. 243-251, 2011.

MINISTÉRIO DA SAÚDE. Secretaria de Atenção à Saúde Coordenação-Geral da Política de Alimentação e Nutrição. Guia alimentar para a população brasileira, promovendo a alimentação saudável. Brasília - DF, 2005.

MOTTA, D. G.; BOOG, M. C. F. Educação nutricional. 3. ed. São Paulo: IBRASA, 1991. $182 p$.

OLIVEIRA, A. B. A. et al. Avaliação da presença de microrganismos indicadores higiênicosanitários em alimentos servidos em escolas públicas de Porto Alegre, Brasil. Ciência \& Saúde Coletiva, Rio de Janeiro, v. 18, n. 4, p. 955-962, 2013.

OLIVEIRA, O.; FISBERG, M. Obesidade na infância e adolescência: uma verdadeira epidemia. Arq. Bras. Endocrinol. Metab., São Paulo, v. 47, n. 2, p. 107-108, 2003.

PIOLTINE, M. B.; SPINELLI, M. G. N. Análise da oferta alimentar em uma escola privada do 
município de São Paulo. Rev. Univap, São José dos Campos, v. 18, n. 31, p. 48-57, 2012.

PRADO, B. G.; NICOLETTI, A. L.; FARIA, C. S. Avaliação Qualitativa das Preparações de Cardápio em uma Unidade de Alimentação e Nutrição de Cuiabá- MT. Cient Ciênc Biol Saúde, Londrina, v. 15, n. 3, p. 219-223, 2013.

PROENÇA, R. P. C. et al. Qualidade nutricional e sensorial na produção de refeições. Nutr. Pauta, São Paulo, v. 13, n. 75, p. 34-45, 2005.

RODRIGUES, V. M.; FIATES, G. M. R. Hábitos alimentares e comportamento de consumo infantil: influência da renda familiar e do hábito de assistir à televisão. Rev. Nutr., Campinas, v. 25, n. 3, p. 353-362, 2012.

VEIROS, M. B.; PROENÇA, R. P. C. P. Avaliação qualitativa das preparações do cardápio em uma unidade de alimentação e nutrição - método AQPC. Nutr. Pauta, São Paulo, v. 11, n. 62, p. 36-42, 2003.

VIDAL G. M.; et al. Avaliação do cardápio de uma unidade de alimentação e Nutrição institucional de Florianópolis, Santa Catarina. In: CONBRAN, 22., 2012, Florianopolis. Anais... Florianópolis: ABNE, 2012.

WORLD HEALTH ORGANIZATION. Diet, nutrition and the prevention of chronic diseases: report of a joint WHO/FAO expert consultation. Geneva: WHO, 2002. 